\author{
G.Palchonok ${ }^{1}$, A.Borodulya ${ }^{1}$, V.Golubeva ${ }^{1}$, B.Leckner ${ }^{2}$, K.-M.Hansson ${ }^{2}$, C. Tullin ${ }^{3}$, \\ J.E.Johnsson ${ }^{4}$
}

\title{
TEMPERATURE AND COMBUSTION KINETICS OF WOOD PELLET CHAR IN A FLUIDIZED BED
}

\author{
${ }^{1}$ A.V.Luikov Heat and Mass Transfer Institute, National Academy of Sciences of Belarus \\ ${ }^{2}$ Chalmers University of Technology, Department of Energy Conversion, Sweden \\ ${ }^{3}$ Swedish National Testing and Research Institute (SP), Sweden \\ ${ }^{4}$ Technical University of Denmark, Department of Chemical Engineering, Denmark
}

Wood pellets are an up-graded biofuel manufactured by drying and compressing of fine or crushed residues like sawdust, cutter shavings, bark. Pellets have a moisture content well below $10 \%$ and a high density $\left(\geq 1000 \mathrm{~kg} / \mathrm{m}^{3}\right)$ and heating value (almost $20 \mathrm{MJ} / \mathrm{kg}$ ). This makes transportation and storage of pellets economically reasonable. Pellets are an alternative to fossil fuels for small size boilers and district heating plants, as well as for small-scale house heating systems. Fluidized bed combustion (FBC) of pellets gives further enhanced ecological and operational advantages.

Despite the low content of fixed carbon typical for biomass (around $20 \mathrm{wt} \%$ ), char combustion is the longest combustion stage. The ratio of the times for char combustion and devolatilization of wood pellets under FBC conditions varies from 5-8 at an oxygen concentration of $21 \%$ to $10-20$ at $8 \%$ [1]. The highly developed pore structure and internal combustion of coarse biomass-char particles might have been a reason for the intense generation of carbon fines by attrition under FBC conditions [2]. This phenomenon was found to contribute to the observed combustion rate as much as heterogeneous combustion of the coarse particle. The combustion-promoted attrition, the product ratio $\mathrm{CO} / \mathrm{CO}_{2}$ of heterogeneous combustion, as well as homogeneous combustion of $\mathrm{CO}$ in the boundary layer affect the temperature of the coarse particle. The above phenomena exemplify the complexity of pellet char combustion and the importance of a detailed knowledge of its mechanisms for practical applications. Here, an experimental study and a theoretical analysis of combustion of a single pellet in a fluidized bed are presented, focused on char temperature and burnout time. Given that FBC of a single particle provides rather well defined boundary conditions, the data obtained can be applied to other combustor types by means of the similarity approach.

Experimental. The experiments have been carried out in a fluidized bed of quartz sand in a $55-\mathrm{mm}$ stainless steel reactor (bed height $75 \mathrm{~mm}$, Sauter-mean bed particle diameter, $\mathrm{d}_{\mathrm{i}}=0.26$ and $0.52 \mathrm{~mm}$; bed particle density, $\rho_{\mathrm{i}}=2540 \mathrm{~kg} / \mathrm{m}^{3}$; bed temperature, $\mathrm{T}_{\mathrm{b}}=873-1073 \mathrm{~K}$; 
fluidizing gas - air at the volume flow rate of $3 \cdot 10^{-4} \mathrm{Nm}^{3} / \mathrm{s}$ and oxygen concentration of 21 wt. \%) and in a $64-\mathrm{mm}$ quartz glass reactor (bed height $13 \mathrm{~mm}, \mathrm{~d}_{\mathrm{i}}=0.3 \mathrm{~mm}, \rho_{\mathrm{i}}=2600 \mathrm{~kg} / \mathrm{m}^{3}, \mathrm{~T}_{\mathrm{b}}$ $=973-1173 \mathrm{~K}$, mixture of air and nitrogen at the volume flow rate of $1.3 \cdot 10^{-4} \mathrm{Nm}^{3} / \mathrm{s}$ and oxygen concentration of 4-14 wt.\%). Both reactors are electrically heated. Four Swedish pellet types were studied. Their properties including estimated pore structure are shown in Table 1. All the pellets were produced without binding additives.

Table 1. Fuel properties

\begin{tabular}{|c|c|c|c|c|}
\hline \multirow[t]{2}{*}{ Property } & \multicolumn{4}{|c|}{ Pellet type } \\
\hline & 1 & 2 & 3 & 4 \\
\hline \multicolumn{5}{|l|}{ ORIGINAL PELLETS } \\
\hline Diameter, $\mathrm{d}_{\mathrm{p}}, \mathrm{mm}$ & 6.5 & 10.5 & 8.3 & 8.1 \\
\hline Length, $L_{p}, \mathrm{~mm}$ & $5-13$ & $6-28$ & $5-29$ & $4-22$ \\
\hline Density, $\rho_{\mathrm{p}}, \mathrm{kg} / \mathrm{m}^{3}$ & 1040 & 1100 & 1200 & 1150 \\
\hline Moisture content, W, wt. \% & 7.5 & 8.0 & 7.7 & 8.4 \\
\hline PROXIMATE ANALYSIS (wt. \%. drv basis) & 79.3 & 78.4 & 79.0 & 75.9 \\
\hline Ash, A & 0.4 & 0.8 & 0.6 & 0.4 \\
\hline Fixed carbon (by difference), $C_{\text {fix }}$ & 20.3 & 20.8 & 20.4 & 23.7 \\
\hline \multicolumn{5}{|l|}{ PELLET CHAR } \\
\hline Initial diameter, $\mathrm{d}_{0} \approx 0.75 \mathrm{~d}_{\mathrm{p}}, \mathrm{m}$ & 4.9 & 7.9 & 6.2 & 6.1 \\
\hline Initial length, $\mathrm{L}_{0} \approx 0.75 \mathrm{~L}_{\mathrm{p}}, \mathrm{m}$ & $4-10$ & $4-21$ & $4-22$ & $3-16$ \\
\hline Density, $\rho=\rho_{p}(1-\mathrm{W} / 100)(1-\mathrm{V} / 100)\left(\mathrm{L}_{p} \mathrm{~d}_{p}{ }^{2} / \mathrm{L}_{0} \mathrm{~d}_{0}{ }^{2}\right), \mathrm{kg} / \mathrm{m}^{3}$ & 470 & 520 & 550 & 600 \\
\hline Porosity, $\varepsilon=1-\rho / \rho_{\text {wall }}, \rho_{\text {wall }}=1540 \mathrm{~kg} / \mathrm{m}^{3}$ & 0.69 & 0.66 & 0.64 & 0.61 \\
\hline Specific surface area, $\mathrm{F}_{\mathrm{i}} \times 10^{-8}, \mathrm{~m}^{-1}$ & 1.53 & 1.52 & 1.51 & 1.46 \\
\hline Mean pore radius, $\left(r_{p}=2 \varepsilon / F_{i}\right) \times 10^{8}, \mathrm{~m}$ & 1.2 & 1.3 & 1.4 & 1.6 \\
\hline Fixed carbon, $Y_{C f x}=C_{f i x} /(1-V / 100)$, wt.\% & 98.1 & 96.3 & 97.1 & 98.3 \\
\hline
\end{tabular}

A special test series was carried out to measure the combustion temperature of pellets type 2. The temperature was measured with a chromel-alumel thermocouple whose junction was pressed into the center of the pellet. The thermocouple wires of a diameter of $0.3 \mathrm{~mm}$ in a thin ceramic insulation allowed some freedom of radial motion of the pellet in the bed. There is always some uncertainty in such measurements due to heat conduction through the wires. However, given that the char temperature is higher than that of the bed, the tests provided a reliable conservative temperature estimate.

A typical routine of measuring the char burnout time was the following: a single pellet was introduced into the hot fluidized bed, and the volatiles extinction time, $t_{v e}$, and the particle burnout time, $t_{c}$, were visually observed from the top of the reactor. The char combustion time was defined as $t_{c}=t_{c}-t_{v e}$. The state of a burning pellet could be easily traced. During devolatilization it was mostly floating on the surface of the bed because of an intensive outflow of gas. The pellet kept its shape close to cylindrical but decreased around $20-30 \%$ in linear size during devolatilization.

The glowing char particles could be distinguished against the darker background of the bed while circulating in the bed, periodically showing themselves at the surface. They gradually decreased in size, but preserved their cylindrical shape. The circulation frequency decreased from 1.0-0.5 to around $0.2 \mathrm{~Hz}$ (the penetration depth rose) as the particle size diminished. Sparkle-like fines were split off the char particle, probably due to attrition. Finally, the particle 
crumbled into a number of sparkles and got lost out of view. At that moment the burnout time was registered, corrected by a half-period of circulation.

In the quartz glass reactor the devolatilization and char burnout times were measured visually as well as by means of gas analysis, following the carbon conversion rate versus time, with both methods being in a good agreement.

Theory. A cylindrical char particle of current diameter $d$ and length $L$ (initial values - $d_{0}$ and $L_{0}$ ) is assumed to burn in air according to the shrinking particle model at constant density. The combustion is assumed to occur under a quasi-steady thermal regime, with particle temperature and temperature-dependent parameters being constant. The latter assumption is based on observed plateau-like temperature versus time dependencies of coarse coal-char particles in a fluidized bed [3]. The mass balance of carbon under the above assumptions reads

$(\partial / \partial t)\left(\pi \mathrm{d}^{2} \mathrm{~L} \rho \mathrm{Y}_{\mathrm{Cfix}} / 4\right)=-\mu \mathrm{k}_{\mathrm{o}} \mathrm{Y}_{\mathrm{O} 2} \rho_{\mathrm{g}}\left(\pi \mathrm{dL}+\pi \mathrm{d}^{2} / 2\right)(1+\mathrm{a})$.

Assuming uniform conditions on the external surface of the particle $(\partial \mathrm{d} / \partial \mathrm{t}=\partial \mathrm{L} / \partial \mathrm{t}=\partial \ell / \partial \mathrm{t})$ and integrating Eqn (1) from $\mathrm{t}=0$ to the char burnout time, $\mathrm{t}_{\mathrm{s}}$, and from $\ell_{0}=\min \left(\mathrm{d}_{0}, \mathrm{~L}_{0}\right)$ to $\ell=0$, one obtains the following quasi-steady estimates of the overall combustion rate,

$\mathrm{k}_{\mathrm{o}}=\ell_{\mathrm{o}} \rho \mathrm{Y}_{\mathrm{Cfix}} /\left(2 \mu \mathrm{Y}_{\mathrm{O} 2} \rho_{\mathrm{g}} \mathrm{t}_{\mathrm{c}}(1+\mathrm{a})\right)$

and total combustion rate (including attrition),

$k_{t}=k_{0}(1+a)$.

The overall rate constant can also be expressed through the serial sum of diffusion and apparent kinetic resistances,

$\mathrm{k}_{\mathrm{o}}=1 /\left(1 / \mathrm{k}_{\mathrm{a}}+1 / \beta\right)$

or of diffusion and true (intrinsic) kinetic resistances,

$\mathrm{k}_{\mathrm{o}}=1 /\left(1 /\left(\mathrm{k} \eta \mathrm{F}_{\mathrm{i}} \gamma\right)+1 / \beta\right)$,

provided that a simple first order reaction with respect to oxygen is assumed.

The efficiency factor, $\eta$, defined as the ratio of reaction rate under pore diffusion resistance and under surface reaction conditions [4], is a function of the Thiele modulus $\eta=((3 T h) \operatorname{coth}(3 T h)-1) /\left(3 T h^{2}\right)$.

Estimates of physical properties of pellet char are shown in Table 1. They are derived from the properties of the original pellets and a mean linear shrinkage during pyrolysis of $25 \%$. The skeletal density of char walls, $\rho_{\text {wall }}=1540 \mathrm{~kg} / \mathrm{m}^{3}$, is adopted from measurements on wood charcoal [5] and used for estimating the porosity of pellet char, $\varepsilon$. The estimates of the specific surface area of pellet char, $F_{\mathrm{i}}=\mathrm{S}_{\mathrm{g}} \rho$, are based on the approximation of data [5] on the specific area per unit mass, $S_{g}$, of birch and spruce char versus porosity, $S_{g}=0.73 \varepsilon^{2.23}$.

Preliminary measurements of internal surface area and pore volume of char of type 2 pellets were made by the methods of mercury porosimetry (macro pore region) and nitrogen adsorption (meso pore region). The char particles were sampled from the batch-scale furnace under grate-combustion conditions. Such conditions did not guarantee the completeness of devolatilization. Assuming that measurements by both methods are additive to represent the total pore surface area and volume (except for micro pores), the following results have been obtained: $F_{i}=0.64 \cdot 10^{8} \mathrm{~m}^{-1}, \varepsilon=0.57, \rho=624 \mathrm{~kg} / \mathrm{m}^{3}, \mathrm{r}_{\mathrm{p}}=1.8 \cdot 10^{-8} \mathrm{~m}$. Compared to estimates given in Table 1, the measured char density is somewhat higher and porosity lower. This supports the possibility of incomplete devolatilization of the samples. Correspondingly, the measured specific surface area is roughly two times lower and the average pore radius two times higher than those shown in Table 1 . In general, however, the measurement results qualitatively agree 
with the estimates. Further measurements with the char samples produced under adequate conditions should provide more accurate data on the porous char structure.

Internal diffusivity of oxygen in pores of less than $1 \mu \mathrm{m}$ in size (which is the case for biomass char [5]) is estimated with account for Knudsen diffusion [4]

$D_{i}=1 /\left(1 / D_{e}+1 / D_{k}\right)$.

The quasi-steady estimate of the temperature of the char particle for an isothermal particle reads

$\mathrm{T}_{\mathrm{a}}=\mathrm{T}_{\mathrm{b}}+\mathrm{k}_{\mathrm{o}} \Delta \mathrm{H} \mathrm{Y}_{\mathrm{O} 2} \rho_{\mathrm{g}} / \boldsymbol{a}$.

The heat of reaction should account for the $\mathrm{CO} / \mathrm{CO}_{2}$ product ratio including postcombustion of $\mathrm{CO}$ within the boundary layer

$\Delta \mathrm{H}=\Delta \mathrm{H}_{\mathrm{CO} 2}(2-\phi)+\Delta \mathrm{H}_{\mathrm{CO}}(\phi-1)$.

The primary $\mathrm{CO} / \mathrm{CO}_{2}$ product ratio under tube-reactor conditions is usually estimated by Arrhenius type expressions, e.g. by Rossberg [6],

$\mathrm{p}=1860 \exp \left(-7220 / \mathrm{T}_{\mathrm{a}}\right)$.

Expressions like Eqn (10) usually significantly overestimate p measured under FBC conditions. Furthermore, the transition from $\mathrm{CO}_{2}$, being the main product at low temperatures, to $\mathrm{CO}$ at high temperatures as predicted by Eqn (10) has been questioned for fluidized beds [79]. Surprisingly, a fairly constant mean value of $p \approx 0.3$ has been established for coal-char combustion in fluidized bed under a wide range of conditions $[8,9]$, covering those studied in the present paper. This result could be explained either by the assumption that $\mathrm{CO}_{2}$ is the main primary product or by post-combustion of $\mathrm{CO}$ in the boundary layer.

Semenov number characterizes the probability and mechanism of homogeneous combustion of $\mathrm{CO}$, with a rate constant estimated for combustion according to simplified first order kinetics [10],

$\mathrm{k}_{\mathrm{CO}}=7.05 \cdot 10^{6} \exp (-96300 / \mathrm{RT})$,

where the temperature of the boundary layer, $T$, is the arithmetic-average of the char particle and the bed. At Se $\leq 0.4 \mathrm{CO}$ mostly escapes from the boundary layer, at $0.4<\mathrm{Se}<2 \mathrm{CO}$ burns within the layer according to the single-film mechanism and at $\mathrm{Se} \geq 2$ according to the double film mechanism [10]. $\mathrm{Se}>100$ corresponds to post-combustion in a thin front.

The detailed procedure of estimating time-average heat $(\alpha)$ and mass $(\beta)$ transfer coefficients to the burning particle in a fluidized bed as functions of the Archimedes number for the inert bed material, Ar, and the char-to-bed particle size ratio, $d_{d} / d_{i}$, is described in $[1,11]$. The averaging procedure presumes that the char particle collapses when its effective diameter, $d_{\epsilon}$, has reached the mean size of the bed particles. To be consistent with the definition of the Thiele modulus, the effective diameter of the char particle is defined as $d_{e}=6 \gamma=\varphi d_{v}$, where $d_{v}$ is the diameter of the volume equivalent sphere and $\varphi$. the shape factor (the ratio of the external surface area of the char particle and a volume equivalent sphere). Unlike in [1], the effect of fluidization velocity on the mass transfer coefficient is taken into account according to [11]. The arithmetic-average temperature of a char particle and the bed is used as reference. The molecular diffusivity of oxygen in air is calculated according to [10], with the reference temperature being that of the particle for char combustion and that of the boundary layer for homogeneous $\mathrm{CO}$ combustion. 
Results and discussion. Figure 1 shows a comparison between typical measured char temperature of $15 \mathrm{~mm}$-long type 2 pellets and estimates by Eqn (8). The horizontal parts of the experimental dependencies (dots) correspond to char combustion, supporting the assumption of the quasi-steady thermal regime. However, the length of these parts is only $15-30 \%$ of the overall char burnout time. The reason is the loosening contact between the char and the thermocouple junction during combustion. The char temperature was higher than that of the bed and increased as the bed temperature rises, but the excess temperature, $\Delta T=T_{a}-T_{b}$, decreased from $120-130 \mathrm{~K}$ at $\mathrm{T}_{\mathrm{b}}=873 \mathrm{~K}$ to $70-100 \mathrm{~K}$ at $1073 \mathrm{~K}$.

As follows from Fig. 1 , if $\mathrm{p}=\mathrm{CO} / \mathrm{CO}_{2}$ is assumed to follow Rossberg's kinetics, Eqn (10), and the attrition-to-combustion rate ratio, $\mathrm{a}=1$, is adopted from [2], Eqn (8) underestimates the experimental data (dotted lines). The best fit of the model predictions based on Rossberg's kinetics (dashed lines) corresponds to $\mathrm{a}=0.4$, which contradicts the data of [2]. On the other hand, estimates by Eqn (8) based on $a=1$ coupled with $\mathrm{p}=0.3$ typical for $\mathrm{FBC}$ conditions (solid lines), agree well with the measurements. (Due to the heat loss by thermal conduction through the thermocouple the actual particle temperature should be somewhat higher than that represented by the symbols in Fig. 1.) The latter coupled mechanism is used in further evaluations throughout the paper, presented in Figs 2-5 and Table 2.

Figure 2 shows experimental data on the total combustion rate, $k_{l}$, evaluated by Eqn (3) versus bed temperature. The symbols in Figs 2-4 (altogether around 170 measurements) represent averaged rate constants for different pellet sizes, obtained under the same operation condition. The relative deviation of the experimental values of $k_{l}$ from the averaged ones presented in Fig. 2 is $3-15 \%$. It follows from Fig. 2, that data points exceed the mass transfer coefficients, probably, due to attrition. Arrhenius-type regression fits,

$k_{t}=A_{t} \exp \left(-E_{t} / R T_{b}\right)$

as shown in Fig. 2 are obtained for all pellet types studied; parameters and deviations are given in Table 2.

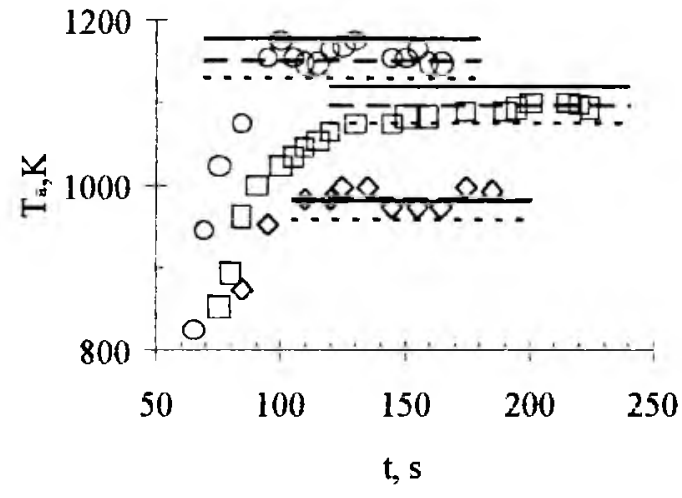

Fig. 1. Comparison between measured (symbols) and estimated by Eqn (8) (lines) char particle temperature. $Y_{\mathrm{O} 2}=0.21 .0-\mathrm{T}_{\mathrm{b}}=1073 \mathrm{~K}, \square-1003$ $\mathrm{K}, \diamond-873 \mathrm{~K}$. Solid line $-\mathrm{a}=1, \mathrm{p}=\mathrm{CO} / \mathrm{CO}_{2}=0.3$. Dashed and dotted lines - $\mathrm{p}$ calculated by Eqn (10), $\mathrm{a}=0.4$ and 1 , respectively

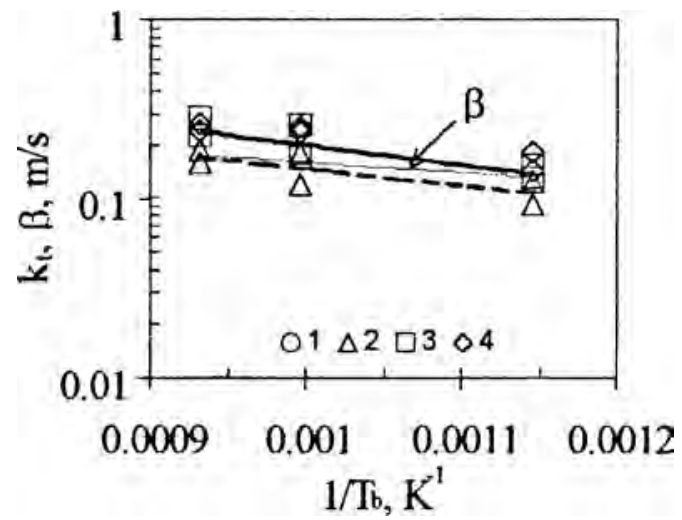

Fig. 2. Total combustion rates (symbols) vs inverse bed temperature. Thicker solid and dashed lines - calculations by Eqn (12) for type 1-4 and 2 pellets, respectively. The thin line - Arrhenius-type trend-line for the mass transfer coefficient. 1-4 pellet types 
Figure 3 shows the averaged apparent and true reaction rates evaluated from Eqns (4) and (5). The relative deviations of the data from the average values of Fig. 3 is $0.4-$ $1 \%$ for the particle temperature, $3-50 \%$ for the apparent rate constant, and $6-110 \%$ for the intrinsic rate constant. The following Arrhenius-type kinetic expressions represent all pellet types studied,

$\mathrm{k}_{\mathrm{a}}=\mathrm{A}_{\mathrm{a}} \exp \left(-\mathrm{E}_{\mathrm{a}} / \mathrm{RT}_{\mathrm{a}}\right)$

$k=A \exp \left(-E / R T_{2}\right)$

The parameters and deviations are given in Table 2 (the overall regression curves are shown in Fig. 3). The analogous evaluation of the kinetics parameters under the assumptions of Rossberg's $\mathrm{CO} / \mathrm{CO}_{2}$ split and the attrition rate ratio of $\mathrm{a}=0.4$ results in much larger relative deviations of data from Eqns (12)-(14) than those of 'Table 2.

The sensitivity of intrinsic kinetics, Eqn (14), to the characteristics of char porous structure was checked by using the preliminary results of mercury porosimetry and $\mathrm{N}_{2}$ adsorption instead of the estimates of char parameters shown in Table 1. Such an evaluation gave insignificantly higher (no more than $30 \%$ ) values of the true reaction rate constant.

The averaged values of the characteristic dimensionless criteria are shown in Fig. 4. The Damköhler number, $\mathrm{Da}=\mathrm{k}_{\alpha} / \beta$, increases from 0.6 to 9.0 as the pellet temperature rises from 920 to 1230 $\mathrm{K}$. This corresponds to the shift of the ratecontrolling stage from the pore diffusion and reaction kinetics to external diffusion through the boundary layer. The Thiele modulus ranges from 10 to 200 , respectively. These values indicate small oxygen penetration depth in pore structure. At higher temperatures of char particles $(T h \approx 200)$ the reaction occurs practically at the external surface. The Semenov number ranges mostly from 0.4 to 2 , showing that $\mathrm{CO}$, even being the only primary product, probably manages to burn out within the boundary layer. These estimates support the findings of [6-9] concerning the $\mathrm{p}=\mathrm{CO} / \mathrm{CO}_{2}$ ratio and the assumption of $p=0.3$ in the present analysis.

The true activation energy values obtained, E, vary from 69 for type 2 pellets to 103-148 $\mathrm{kJ} / \mathrm{mol}$ for the other pellets studied (Table 2). These values are slightly lower than the literature data for coal chars (113 to $163 \mathrm{~kJ} / \mathrm{mol}$ ), reported for the first order reaction [12]. The discrepancy for type 2 pellets might be due to differences in the porous structure and the size of the pellet and coal chars studied. In any case, the physical properties of the pellet char, roughly estimated in the present analysis, need to be more carefully studied. 
Table 2. Kinetics parameters and standard deviations

\begin{tabular}{|c|c|c|c|c|}
\hline \multirow{2}{*}{$\begin{array}{c}\text { Kinetics } \\
\text { expression }\end{array}$} & \multirow[t]{2}{*}{ Pellet No. } & \multicolumn{2}{|c|}{ Kinetic parameter } & \multirow{2}{*}{$\begin{array}{c}\text { Relative } \\
\text { deviation, \% }\end{array}$} \\
\hline & & $A_{i}, m / s$ & $\mathrm{E}_{\mathrm{i}}, \mathrm{kJ} / \mathrm{mol}$ & \\
\hline \multirow[t]{5}{*}{ Eqn (12) } & 1 & 2.9 & 21.8 & 25 \\
\hline & 2 & 1.2 & 17.6 & 19 \\
\hline & 3 & 3.2 & 22.6 & 17 \\
\hline & 4 & 2.1 & 18.4 & 13 \\
\hline & $1-4$ & 2.6 & 21.3 & 23 \\
\hline \multirow[t]{5}{*}{ Eqn (13) } & 1 & 1669.8 & 76.8 & 66 \\
\hline & 2 & 10.3 & 37.2 & 40 \\
\hline & 3 & 682.3 & 68.4 & 57 \\
\hline & 4 & 158.4 & 54.4 & 38 \\
\hline & $1-4$ & 336.6 & 63.4 & 65 \\
\hline \multirow[t]{5}{*}{ Eqn (14) } & 1 & 2230.3 & 148.4 & 182 \\
\hline & 2 & 0.094 & 69.5 & 96 \\
\hline & 3 & 572.8 & 134.3 & 154 \\
\hline & 4 & 22.9 & 103.3 & 77 \\
\hline & $1-4$ & 112.9 & 122.7 & 205 \\
\hline
\end{tabular}

Given that the Damköhler number is of the order of 1 at moderate temperatures, Eqn (4) leads to $\mathrm{k}_{\mathrm{o}} \approx \beta / 2$ and Eqn (8) can be rewritten as

$\mathrm{T}_{\mathrm{a}} \approx \mathrm{T}_{\mathrm{b}}+0.5 \Delta \mathrm{HY}_{\mathrm{O} 2} \rho_{\mathrm{g}}(\beta / \alpha)$.

Taking into account that $\alpha=f_{1}\left(A r, d_{d} / d_{i}\right)$ and $\beta=f_{2}\left(A r, d_{d} / d_{i}\right)$ with the effect of the particle size ratio described in the same way [11], one can represent the mass-to-heat coefficient ratio as $\beta / \alpha=f_{3}(A r)$. At a constant split ratio and oxygen concentration this leads to $\left(T_{2}-T_{b}\right) \approx f(A r)$.

Figure (5) shows the normalized excess particle temperatures estimated by Eqn (8) versus the Archimedes number. The data are approximated by the power functions, $\left(\mathrm{T}_{\mathrm{a}}-\mathrm{T}_{\mathrm{b}}\right) / \mathrm{T}_{\mathrm{b}}=0.027 \mathrm{Ar}^{0.25}$

for type 1,3 , and 4 pellets of $6-8 \mathrm{~mm}$ diameter and

$\left(\mathrm{T}_{\mathrm{a}}-\mathrm{T}_{\mathrm{b}}\right) / \mathrm{T}_{\mathrm{b}}=0.018 \mathrm{Ar}^{0.27}$

for type 2 pellets of $10 \mathrm{~mm}$ diameter.

As follows from Fig. 5, Eqn (16) satisfactorily describes measured temperatures of type 2 pellets. Equations (15) and (16) could be used for crude estimations of maximum temperature of pellet char particles under FBC conditions.

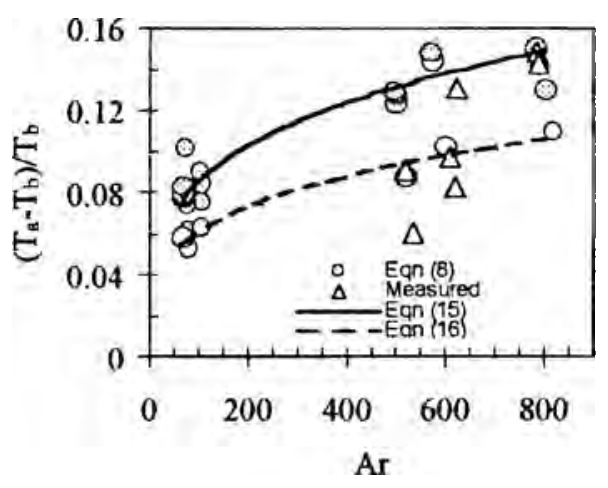

Fig. 5. Normalized excess temperature of char particle vs Archimedes number. Closed symbols and solid line - type 1, 3,4 pellets, open symbols and dashed lines - type 2 pellets

The above results and discussion refer to an oxygen concentration of $Y_{02}=0.21$. The kinetics parameters obtained (Table 2) and Eqns (1)(9) were used to estimate the pellet char burnout time at the oxygen content of 0.08 . The results show a good agreement with measured data, the relative deviation is around $11 \%$. 


\section{Conclusions}

Combustion mechanisms of char from wood pellets have been studied under FBC conditions, focusing on char temperature and burnout time.

The char combustion temperature was practically constant with time; at least during the first $15-30 \%$ of the total combustion time. This enabled a simplified quasi-steady evaluation of combustion kinetics and temperature, based on the measured burnout times. The char particle temperature was $70-130 \mathrm{~K}$ higher than the bed temperature and increased as the latter rose, with the excess temperature decreasing at the same time.

Comparison of measured char temperatures and those evaluated from the experimental burnout times confirms recently published information [2] of a highly intensive combustionpromoted attrition of carbon fines accompanying heterogeneous combustion of coarse biomass char particles. The ratio of attrition and combustion rates of char from wood pellets was found to be $\mathrm{a}=1$ and 0.4 , provided that the molar $\mathrm{CO} / \mathrm{CO}_{2}$ product ratio is close to $\mathrm{p}=0.3$ or follows Rossberg's kinetics [6]. The former agrees with the estimates of the Semenov number, showing that the primary $\mathrm{CO}$ should mostly burn within the boundary layer of the fuel particle.

The Damköhler number varied from 0.6 at lower pellet temperatures to 9 at higher temperatures. This corresponds to the shift of the rate-controlling stage from the pore diffusion and reaction kinetics to external diffusion through the boundary layer. The Thiele modulus ranged from 10 to 200 , respectively. These values indicate that oxygen penetration depth in pore structure was small and decreased as the pellet temperature rose.

Arrhenius-type expressions are obtained for the quasi-steady total combustion rate (including attrition), apparent and true reaction rates for a simple first order reaction. The former two expressions provide accuracy acceptable for engineering applications, whereas the true kinetics parameters need more precise determination, based on detailed studies of the properties of pellet char. The above kinetic parameters are, in truth, only crude estimates and further study of time resolved char reactivity is needed.

\section{Errata}

In paper [1] the right hand side of Eqn (12) should read 2 instead of 4 in the denominator.

\section{Acknowledgements}

The Swedish part of the work, including a grant for G.Palchonok, was financed by the Swedish Energy Administration, which is hereby gratefully acknowledged.

\section{Notations}

A - frequency factor; a - ratio of attrition and combustion rates, Ar - Archimedes number for inert bed material; $\mathrm{D}$ - molecular diffusivity; $\mathrm{D}_{\mathrm{e}}$ - effective diffusivity, $\mathrm{D}_{\mathrm{e}}=\mathrm{D} \varepsilon / \tau ; \mathrm{D}_{\mathrm{k}}-$ Knudsen diffusivity, $\mathrm{D}_{\mathrm{k}}=\mathrm{r}_{\mathrm{p}}(3 / 4)\left(2 \mathrm{RT}_{\mathrm{a}} /\left(\pi \mathrm{M}_{\mathrm{O} 2}\right)\right)^{1 / 2} ; \mathrm{d}_{\mathrm{c}}$ - effective diameter of char particle; $\mathrm{d}_{\mathrm{i}}$ - mean diameter of bed particles; $\mathrm{Da}$ - Damköhler number, $\mathrm{Da}=\mathrm{k}_{\mathrm{a}} / \beta ; \mathrm{E}$ - activation energy; $\mathrm{F}_{\mathrm{i}}-$ specific surface area of the porous char particle, $F_{i}=S_{t} / V ; k, k_{a}$ - true and apparent reaction rate constants; $k_{,}$- overall combustion rate; $k_{\mathfrak{l}}$ - total combustion and attrition rate; $\mathrm{M}_{\mathrm{C}}, \mathrm{M}_{\mathrm{O} 2}-$ molecular mass of carbon and oxygen; $\mathrm{p}-\mathrm{CO} / \mathrm{CO}_{2}$ molar ratio; $\mathrm{R}$ - universal gas constant; $\mathrm{r}_{\mathrm{p}}$ mean pore radius; $S_{c}, S_{1}$ - external and total surface area of the particle; $S_{\mathrm{g}}$ - total specific area per unit mass; $\mathrm{Se}=\left(\mathrm{k}_{\mathrm{CO}} \mathrm{D}\right)^{1 / 2} / \beta$ - Semenov number; $\mathrm{t}$ - time; $\mathrm{T}_{2}$ - absolute particle temperature; $\mathrm{T}_{\mathrm{b}}$ is absolute bed temperature, $\mathrm{Th}$ - Thiele modulus, $T h=\gamma\left(k F_{i} / D_{i}\right)^{1 / 2} ; \mathrm{V}-$ particle volume; $Y_{\mathrm{Cfix}}, \mathrm{Y}_{\mathrm{O} 2}$ - mass fractions of fixed carbon in char and oxygen in the bulk of 
the fluidizing gas; $\alpha$ - overall heat transfer coefficient, including thermal radiation; $\beta$-porosity mass transfer coefficient; $\gamma$ - effective particle radius, $\gamma=\mathrm{V} / \mathrm{S}_{e} ; \Delta \mathrm{H}$ - reaction heat absorbed by the burning char particle; $\Delta \mathrm{H}_{\mathrm{CO} 2}, \Delta \mathrm{H}_{\mathrm{CO}}$ - reaction enthalpies for complete and partial carbon oxidation; $\eta$ - efficiency factor; $\varepsilon$-char porosity; $\phi$ - carbon-to-oxygen molar ratio, $\phi=(2 \mathrm{p}+2) /(\mathrm{p}+2) ; \mu$ - stoichiometric ratio, $\mu=\phi \cdot \mathrm{M}_{\mathrm{C}} \mathrm{M}_{\mathrm{O} 2} ; \rho, \rho_{\mathrm{B}}$ - char and gas densities; $\tau$ tortuosity, $\tau=2^{1 / 2}$. Subscripts: $a$ - apparent, active (burning) particle; $b$ - bed; $i$-internal; $t$ total.

\section{References}

1. Borodulya A.V., Dikalenko V.I., Palchonok G.I., Leckner B., Hansson K.-M., Tullin C. Combustion kinetics of wood pellets in fluidized bed // News of National Academy of Sciences of Belarus. Series of Engineering Physics. 1999. N 2. P. 115-123 (in Russian).

2. Salatino P., Scala F., Chirone R. Fluidized-bed combustion of a biomass char: the influence of carbon attrition and fines postcombustion on fixed carbon conversion $/ / 27^{\text {th }}$ Symp. (Int.) on Combustion, The Combustion Institute, Pittsburg, PA, 1996. P. 3103-3110.

3. Borodulya V.A., Palchonok G.I., Vasiljev G.G., Dryabin V.A., Galerstein D.M. Heat and mass transfer and combustion kinetics of solid fuel in a fluidized bed // Int. School-Seminar on Heat \& Mass Transfer Problems in Advanced Technologies of Combustion and Gasification of Solid Fuel (Minsk, 1988). Minsk: A.V.Luikov Heat \& Mass Transfer Institute. 1988. Vol. 2. P. 3-23 (in Russian)

4. Froment G.F., Bischoff K.B. Chemical Reactor Analysis and Design, New York: John Wiley \& Sons, 1979.

5. Grønli M. A Theoretical and Experimental Study of the Thermal Degradation of Biomass // Doctoral Thesis. The Norwegian University of Science and Technology, Trondheim, 1996.

6. Rossberg M. Experimentelle ergebnisse uber die primarreactionen bei der kohlenstoffverbrennung // Z. Electrochem. 1956. Vol. 60. P. 952-956.

7. Hayhurst A.N., Parmar M.S. Does solid carbon burn in oxygen to give the gaseous intermediate $\mathrm{CO}$ or produce $\mathrm{CO}_{2}$ directly? Some experiments in a hot bed of sand fluidized by air // Chem. Eng. Sci. 1998. Vol. 53. P. 427-438.

8. Prins W. Fluidized bed combustion of a single particle // Doctoral Thesis. Twente University, The Netherlands, 1987.

9. Linjewille T.M., Gururajan V.S., Agarwal P.K. $\mathrm{CO} / \mathrm{CO}_{2}$ product ratio from the combustion of petroleum coke spheres in an incipiently fluidized bed // Chem. Eng. Sci. 1995. Vol. 50. P. 1881-1888.

10. Fundamentals of Practical Combustion Theory / Ed V.V. Pomerantsev. Leningrad: Energoatomizdat, 1987 (in Russian).

11. Palchonok G.I. Heat and Mass Transfer to a Single Particle in Fluidized Bed // Doctoral Thesis. Chalmers University of Technology, Göteborg, Sweden, 1998.

12. Smith I.W. The intrinsic reactivity of carbons to oxygen // Fuel. 1978. Vol. 57. P. 409-414. 